\section{Instructions to authors}

Transactions of the Royal Society of Edinburgh: Earth Sciences appears quarterly, publishing studies on all aspects of the earth sciences and related planetary sciences. Substantial contributions to both information and understanding that emphasise principles and are relevant to a worldwide readership are welcome. Normally there is an upper limit of 25000 words, but most contributions are expected to be shorter. Discussions of papers previously published in the Transactions and reviews of topics of current interest are also invited. There are no page charges but subventions towards cost are welcome. If the use of foldouts or colour illustrations is envisaged, the Editorial Office should be consulted prior to submission.

\section{Submission}

Membership of the Society is not a pre-requisite for submission. Three copies of manuscripts should be sent to the Publications Secretary, The Royal Society of Edinburgh, 22 George Street, Edinburgh EH2 2PQ, Scotland. Three copies of illustrations at publication size should also be submitted; for these sets, photocopies of line drawings are adequate, but not of photographs. Illustrations suitable for reproduction (see 3.1) may be requested subsequently. All submissions will be sent to two reviewers. Papers by more than one author must be submitted with a statement signed by each author, to the effect that the paper in its entirety is approved by the joint authors and naming the author who will be responsible for correspondence.

\section{Preparation of papers \\ 2.1. Manuscripts}

Manuscripts should be typed on A4 $(295 \times 210 \mathrm{~mm})$ or quarto paper with double spacing throughout and wide margins. A title that is concise and informative, a heading of not more than 50 typewriter strokes for use at the top of text pages and name(s) of author(s) are to be given on the first page. An abstract of not more than 200 words, intelligible without reference to the text or references, should be given on the second page, with a list of key words not in the title making up no more than 150 typewriter strokes. The text should begin on the third page. Where possible, annotated illustrations and tables should be used in place of text. Give full postal address(es) at the end of the references. Tables and a list of figure captions should be on separate pages.

Editorial details. Words to be printed in italics, e.g. names of taxa, should be underlined. Use capital letters for formal terms only, in both text and headings. The metric system should be used throughout. Abbreviations should omit the full-stop, e.g. $2 \mathrm{~mm}, 3 \mathrm{~km}$ and $6 \mathrm{~kb}$. Compass points are to be abbreviated to N, NW, NW-SE etc. Map references should be in square brackets, e.g. [NM 4437 0293]. Do not use footnotes except in tables. Examples of references in the text are: Jennings and Smith (1967) record ... . Bracketed references should be as follows: (James 1931), (Jennings \& Smith 1967, p. 132), (Jenkins 1947, 1950; Brock 1975). Indicate in the margins approximate positions for insertion of illustrations and tables. For particular treatment of palaeontological specialities consult PALAEONTOLOGY $15,676-81$.

\subsection{Headings}

Primary headings, including Acknowledgements and References, are to be numbered 1,2,3 etc. (as in these Instructions) and secondary headings $1.1,1.2,1.3$ etc.; these are to begin at the left-hand margin and should not be underlined.
Show tertiary headings by wavy underlining. These should be indented and followed by a full-stop, four spaces and then the text of the sub-section. The introductory section requires no heading. Cross-references in the text should be to a section or sub-section, e.g. (see 2.3), not to a page.

\section{Illustrations and tables}

\subsection{Ilustrations}

Illustrations, labelled figures (Fig. 1,2,3 etc.) are printed within the body of the text at column $(85 \mathrm{~mm})$ or page $(177 \mathrm{~mm})$ width, or page length $(253 \mathrm{~mm})$, but allowance must be made for figure captions. Where appropriate, group material into one figure and label a, b, c etc. In the case of groups of photographs, labels and annotation should be on the appropriate photograph, not in the space between photographs. No lettering should be less than $1 \mathrm{~mm}$ high at reproduction size (the use of capital letters throughout improves clarity after reduction). Transfer lettering is preferred. Large figures can be subdivided for reproduction on facing pages. Photographs should be high quality glossy prints with good contrast at final size and with a scale, or magnification in the caption. They should be mounted on white card, even if a black background is required in the published version (this requirement should be specified in an accompanying letter). In the case of fossil illustrations illumination should be top left. Originals of line drawings are usually required, either at publication size, or $\times 150 \%$, but high quality prints on matt paper at publication size may be acceptable.

\subsection{Tables}

Tables $(1,2,3$ etc.) will generally be set up in type and reproduced at column or page width, although certain tables are better presented using transfer lettering; these should be submitted in the same way as line illustrations. Each table should have a heading and be on a separate sheet. For layout of analytical data see tables published in previous issues. Authors will be asked to send published analyses of igneous rocks to the UK-IGBA file.

\section{References}

Set out as indicated below. Abbreviate journal and series titles according to Part 2 (1975) of BS 4148 (The abbreviation of titles of periodicals. Word-abbreviation list. London: British Standards Institution). This system uses capitals throughout and no full-stops. Authors who are unable to obtain this list should give journal titles in full (in capitals). Indicate volume numbers of journals and series by wavy underlining and book titles by single underlining.

Amstutz, G. C. 1968. Spilites and Spilitic Rocks. In Hess, H. H. \& Poldervaart, A. (eds) Basalts, 737-53. New York: Interscience.

Dick, J. R. F. 1978. On the Carboniferous shark Tristychius arcuatus Agassiz from Scotland. TRANS R SOC EDINBURGH 70, 63-109.

Duff, K. L. 1978. Bivalvia from the English Lower Oxford Clay (Middle Jurassic). PALAEONTOGR SOC MONOGR.

Ferguson, J. \& Currie, K. L. 1971. Evidence of liquid immiscibility in ultrabasic dikes, Ontario. J PETROL 12, 501-85.

Hatch, F. H., Wells, A. K. \& Wells, M. K. 1972. Petrology of the Igneous Rocks, 13th edn. London: George Allen \& Unwin.

\section{Proofs and offprints}

One set of proofs will be sent to the author (or senior author of a joint paper). Fifty free offprints are provided and additional copies can be ordered when proofs are returned. 


\section{TRANSACTIONS OF \\ THE ROYAL SOCIETY OF EDINBURGH: \\ EARTH SCIENCES}

SCOTT, R. A., PATTRICK, R. A. D. and POLYA, D. A.

Origin of sulphur in metamorphosed stratabound mineralisation from the Argyll Group Dalradian of Scotland

BRAITHWAITE, C. J. R.

Dolomites, a review of origins, geometry and textures

GALTIER, J. and SCOTT, A. C.

Stanwoodia, a new genus of probable early gymnosperms from the Dinantian of East Kirkton, Scotland

RAMSKÖLD, L.

The perforated trilobite Laethoprusia gen. nov., and the phylogeny of Koneprusia and Isoprusia (Odontopleuridae, Koneprusiinae)

RAMSKÖLD, L.

Pattern and process in the evolution of the Odontopleuridae (Trilobita). The Selenopeltinae and Ceratocephalinae

(Issued on 19 August 1991)

Published by the Royal Society of Edinburgh

22 George Street, Edinburgh EH2 2PQ

Printed in Northern Ireland

by The Universities Press (Belfast) Ltd. 